\title{
Identification and Prioritization of the Criteria Affecting the Performance of the Permit-to-Work System in an Oil Refinery using a Fuzzy Delphi Method and Fuzzy Analytical Hierarchy Process
}

\author{
Seyed Mahdi Mousavi ${ }^{1}$ (D) ,Ali Karimi ${ }^{2, *}$, Seyed Abolfazl Zakerian³ ${ }^{3}$, Mahsa Jahadi Naeni ${ }^{4}$ \\ ${ }^{1}$ MSc of Occupational Health Engineering, School of Public Health, Tehran University of Medical Sciences, Tehran, Iran \\ ${ }^{2}$ Associate Professor, Department of Occupational Health Engineering, School of Public Health, Tehran University of \\ Medical Sciences, Tehran, Iran \\ ${ }^{3}$ Professor, Department Occupational Health Engineering, School of Public Health, Tehran University of Medical Sciences, \\ Tehran, Iran \\ ${ }^{4}$ MSc of Occupational Health Engineering, School of Public Health, Isfahan University of Medical Sciences, Isfahan, Iran \\ * Corresponding Author: Ali Karimi, Department of Occupational Health Engineering, School of Public Health, Tehran \\ University of Medical Sciences, Tehran, Iran.Email: a_karimi@sina.tums.ac.ir
}

\section{Received: 17/07/2020 Accepted: 11/01/2021}

\section{How to Cite this Article:}

Mousavi S, Karimi A, Zakerian S, Jahadi Naeni M. Identification and Prioritization of the Criteria Affecting the Performance of the Permit-to-Work System in an Oil Refinery using a Fuzzy Delphi Method and Fuzzy Analytical Hierarchy Process. J Occup Hyg Eng. 2021; 8(1): 37-45. DOI: 10.29252/johe.8.1.37

\section{Abstract}

Background and Objective: Permit-to-work system is a formal, documented, and written system aiming at controlling the risk of occupations that are considered potentially dangerous. This study aimed to identify and prioritize the criteria affecting the performance of the permit-to-work system in an oil refinery.

Materials and Methods: The present study was designed and implemented in three steps. In the first step, the primary research criteria were identified after reviewing previous studies and conducting interviews with experts. In the second step, the Fuzzy Delphi method was used to determine the final criteria after obtaining the opinions of 25 experts regarding the primary criteria. Finally, the fuzzy hierarchical analysis method was utilized to weigh and prioritize the identified criteria.

Results: The result of the Fuzzy Delphi method showed that six criteria affected the performance of the permit-to-work system. These criteria included the hazard identification and risk assessment, training and competence of individuals, preventive actions, communication, responsibility, and coordination. The prioritization of these criteria using fuzzy hierarchical analysis showed that responsibility (final weight 0.191), as well as coordination and communication (final weight 0.134 ) obtained the highest and lowest importance among the identified criteria, respectively.

Conclusion: In this study, a model of decision-making based on Delphi methods and fuzzy hierarchical analysis was introduced to identify the factors affecting the performance of the permit-to-work system in an oil refinery.

Keywords: Delphi Fuzzy; Fuzzy Analytical Hierarchy Process; Oil Refinery; Permit to Work System 
dof: $10.29252 /$ johe.8.1.37

\title{
شناسايى و اولويتبندى معيار هاى مؤثر بر عملكرد سيستم مجوز كار با استفاده از روش دلفى و روش تحليل سلسلهمراتبى فازى (FAHP) در يك پالايشكاه نفت
}

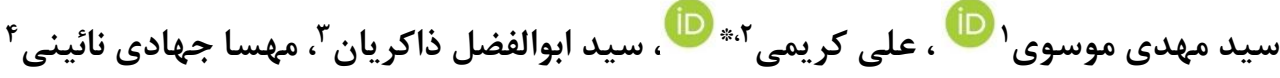

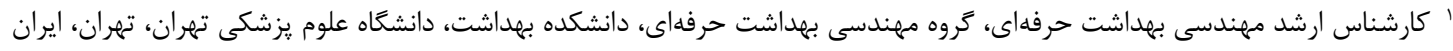

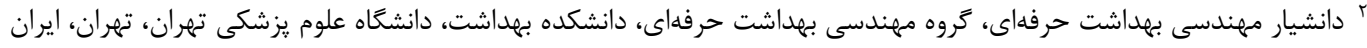

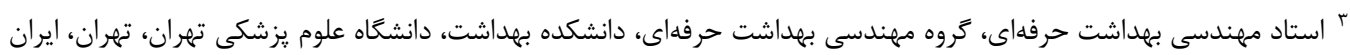

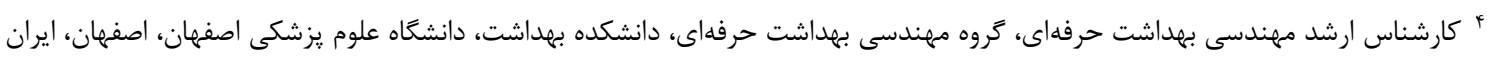

* * نويسنده مسئول: على كريمى، كروه مهندسى بهداشت حرفهاى، دانشكده بهداشت، دانشعاه علوم يزشكى تهران، تهران، ايران.

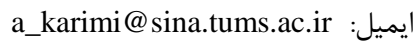

\begin{tabular}{|c|c|}
\hline جكيده & \\
\hline سابقه و هدف: سيستم مجوز كار يك سيستم رسمى، مستند و مكتوب مىباشد كه هدف اصلى آن كنترل & 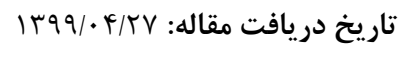 \\
\hline خطر مشاغلى است كه بالقوه خطرناك در نظر كرفته مىشوند. در اين راستا، مطالعه حاضر با هدف شناسايى & 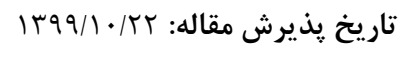 \\
\hline و اولويتبندى معيارهاى مؤثر بر عملكرد سيستم مجوز كار در يك پالايشگاه نفت انجام شد. & \\
\hline مواد و روشها: يزوهش حاضر در سه كام طراحى و اجرا شد. در گام اول با بررسى مطالعات كذشته و & تمامى حقوق نشر براى دانشكاه علوم \\
\hline انجام مصاحبه با خبر كان، معيارهاى اوليه يزوهش مشخص شدند. در گام دوم به منظور تعيين معيارهاى & \\
\hline نهايى، نظر ه خ خبره در خصوص معيارهاى اوليه با استفاده از روش دلفى فازى جمع آورى و تجميع گرديد. & \\
\hline در نهايت به منظور وزندهى و الويتبندى معيارهاى شناسايى شده از روش تحليل سلسلهمراتبى فازى & \\
\hline 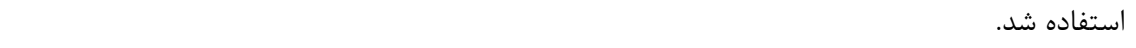 & \\
\hline يافتهها: نتايج دلفى فازى نشان دادند كه شش معيار شناسايى خطر و ارزيابى ريسك، آموزش و صلاحيت & \\
\hline افراد، اقدامات بيشخيرانه، ارتباطات، مسئوليتيذيرى و هماهنكى، معيارهاى مؤثر بر عملكرد سيستم مجوز كار & \\
\hline مىباشند. اولويتبندى معيارها با استفاده از روش تحليل سلسلهمراتبى فازى نشان داد كه معيار & \\
\hline 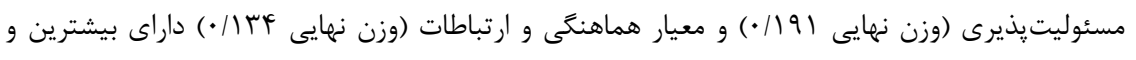 & \\
\hline كمترين اهميت در بين معيارهاى شناسايى مىباشند. & \\
\hline نتيجه كيرى: در اين مطالعه الكويى از تصميمَيرى براساس روشهاى دلفى و تحليل سلسلهمراتبى فازى & \\
\hline جهت شناسايى عوامل مؤثر بر عملكرد سيستم مجوز كار در يك پالايشعاه نفت معرفى گرديد. & \\
\hline وازَّان كليدى: پالايشعاه نفت؛ تحليل سلسلهمراتبى فازى؛ سيستم مجوز كار؛ دلفى فازى & \\
\hline
\end{tabular}

ماهشهر، انفجار در مخزن شيميايى شازند اراك و همجنين وقوع انفجار در يتروشيمى بوعلى سينا اشاره كرد [هـإ].

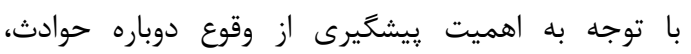

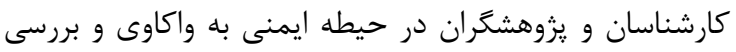

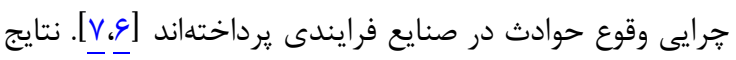
تحقيقات اسكات آشكار كرد كه وقوع حوادث در در صنايع صرايندى برد فردايند با انجام عمليات تعميرات اساسى و وقوع نقص در سيستم مجوز

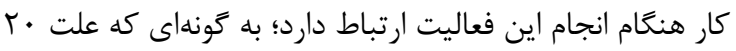

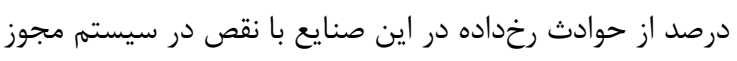

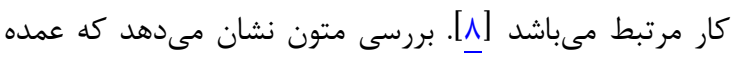

حوادثى كه هر ساله در صنايع فرايندى مانند پالايشخاههاى

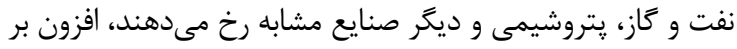

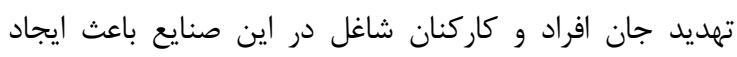

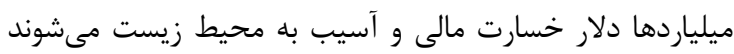

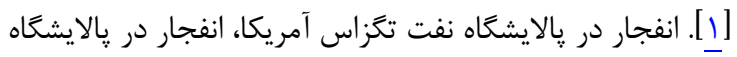

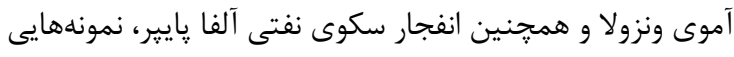

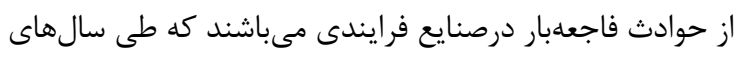

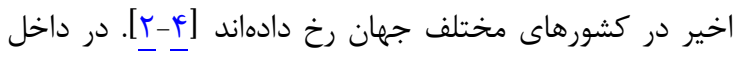

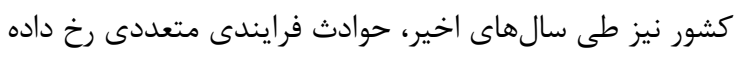

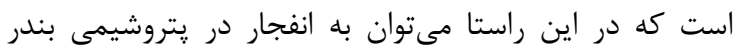


تصميمزيرندگان اغلب به دليل طبيعت فازى و عدم قطعيت

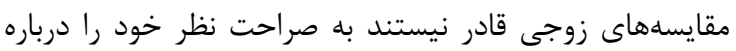

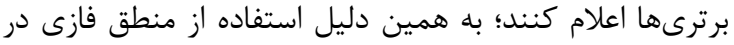

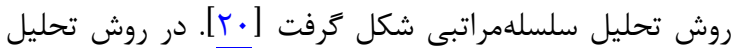
سلسلهمراتبى فازى از خبر كان خواسته مىشود عناصر هر سطح

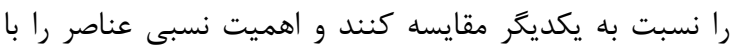
استفاده از اعداد فازى بيان نمايند. تاكنون در مطالعات بسيارى

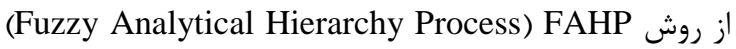
به منظور اولويتبندى معيارها استفادهشده است. اصغرى در سال هوسا به منظور الويتبندى معيارهاى مؤثر در انتخاب يك إنى

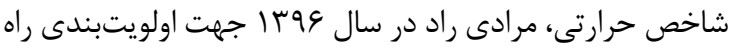

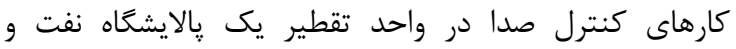

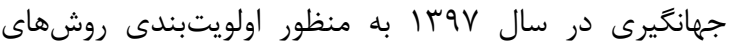

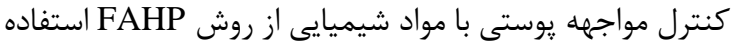

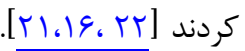
به منظور ارتقاى عملكرد سيستم مجوز كار در ايجاد محيط

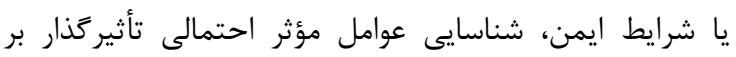

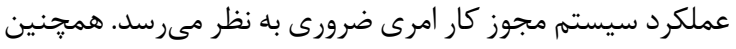

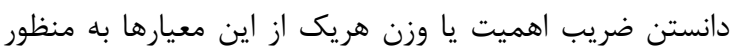

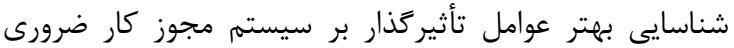

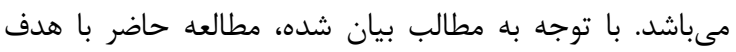

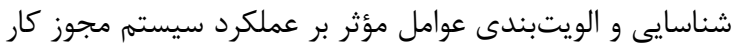

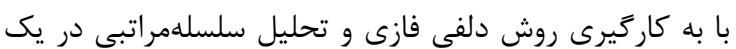
يالايشگاه نفت انجام شد.

\section{روش كار}

مطالعه حاضـــر از نوع توصــيفى - تحليلى بوده و در ســال 19 זا در يك يالاي شكاه نفت در جنوب ايران انجام شده ا ست.

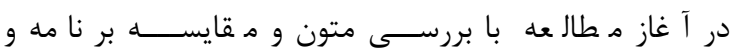

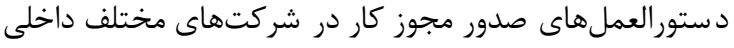

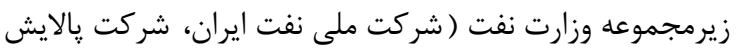

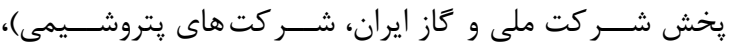

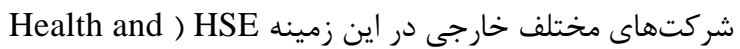
International) OGP ، TOTAL ،Executive Safety SHELL ،Association of Oil \& Gas Producers

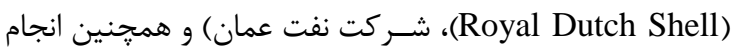
مصاحبه با خبر گان دانشگاهى و صنعتى آشنا با سيستم مجوز

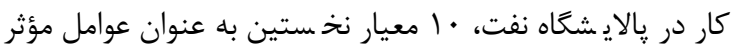
بر عملكرد سيستم مجوز كار در نظر گرفته شدند.

\section{روش دلفى فازى}

در كام اول تيمى متشكل از ه ف نفر خبره تشكيل شد و هدف

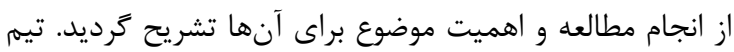

حوادث رخداده در صنايع فرايندى با فعاليتهاى تعمير و نتخهدارى

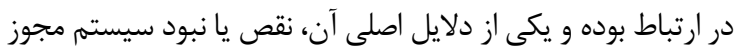

كار مىباشد [9].

سيستم مجوز كار يك سيستم رسمى و مستند براى كنترل

فعاليتهايى است كه به طور بالقوه خطرناك محسوب مىشوند.

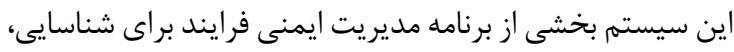

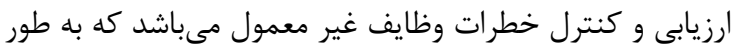
بالقوه خطرناك در نظر گرفته مىشوند. اين سيستم همانند ساير سيستمها از اجزايى تشكيل شده است كه هدف نهايى آن آن ايجاد

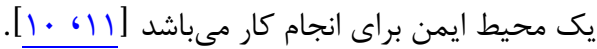

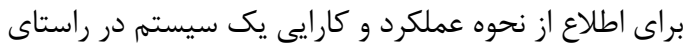

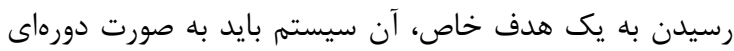

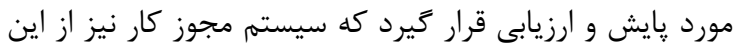

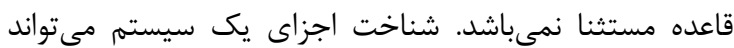

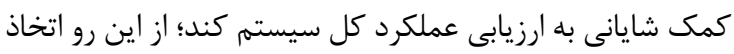

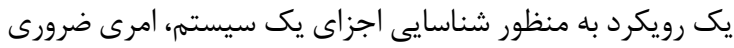

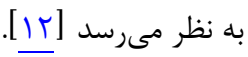
در يزوهشهاى كيفى كه جنبه اكتشافى داشته و شناسايى

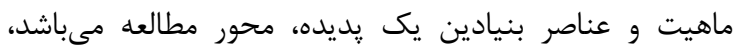

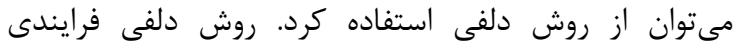

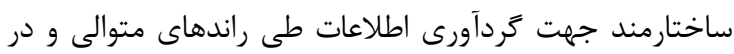

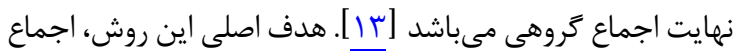

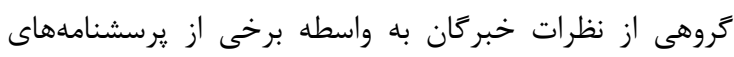

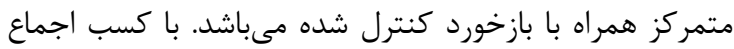

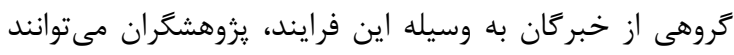

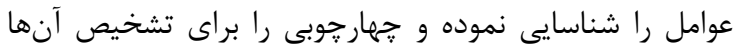

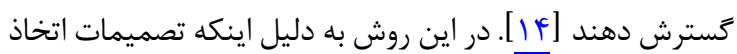

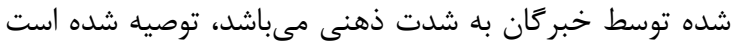

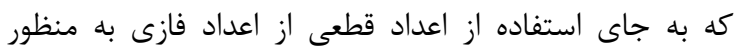

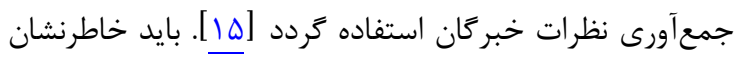

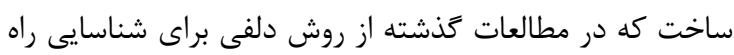

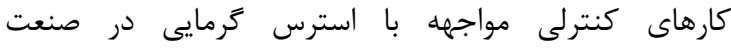
لاستيكسازى، شناسايى معيارهاى انتخاب راهكار كنترل صدا دارئ در

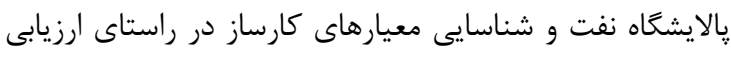

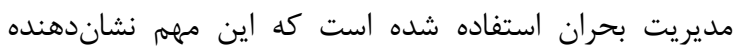
مقبوليت اين روش در حيطههاى مختلف ايمنى و وبهداشت ائفاده

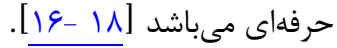

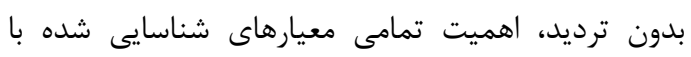

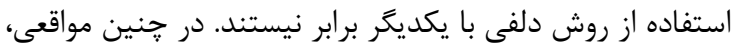

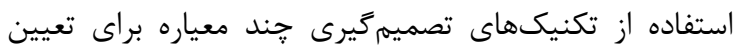

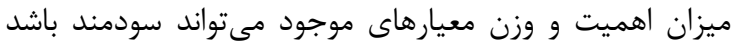

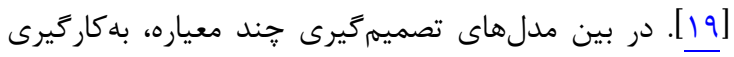

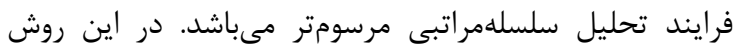


به منظور تجميع نظر خبركان از روابط رياضى حاكم بر اعداد فازى

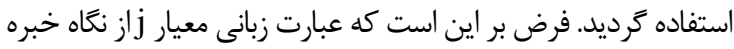

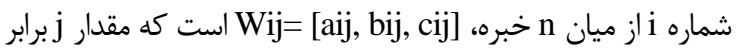

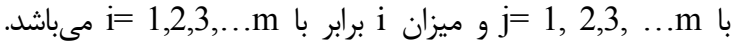

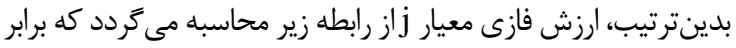
با بaj, bj, cj]
$\mathrm{aj}=\min$
(1)
$\mathrm{bj}=\frac{1}{n} \sum_{i=1}^{n} b j$
(ז) (זبط
$c j=\max$
رابطه (")

در ادامه به منظور ديفازى كردن از رابطه F استفاده كرديد. $\mathrm{Sj}=\frac{a j+b j+c j}{3} \mathrm{i}=1,2, \ldots \mathrm{m}$

(i) (ابطه

در اين مطالعه شرط اجماع يا توافق خبركان زمانى محقق كرديد

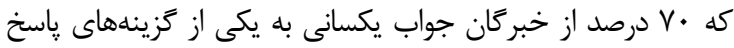
براى هر معيار دادند.

\section{روش تحليل سلسلهمراتبى فازى}

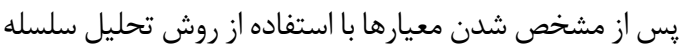

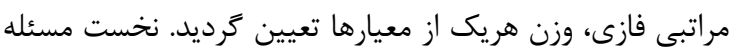

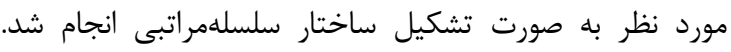

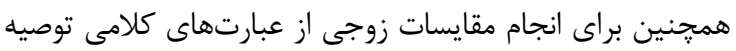

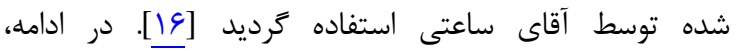

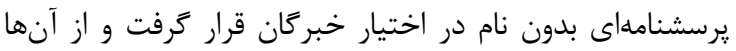

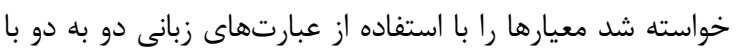

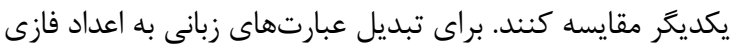
از جدول r استفاده كرديد.

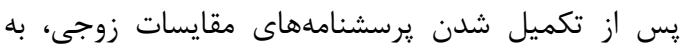

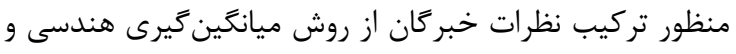

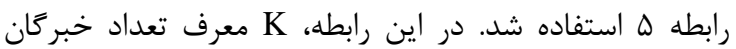

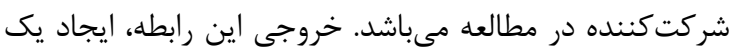

جدول r: تبديل وازمهاى زبانى به اعداد فازى

\begin{tabular}{|c|c|c|c|}
\hline معكوس فازى & فازى اعداد & درازه زبانى اهميت & درجيه \\
\hline$(1,1,1)$ & $(1,1,1)$ & برابر & 1 \\
\hline$\left(\cdot / \Psi^{\prime} \cdot \cdot \mid \Delta_{6} l\right)$ & $(1, r, r)$ & برترى بسيار كم & r \\
\hline$\left(\cdot / T \Delta_{\bullet} \cdot / \Gamma r_{\bullet} \cdot / \Delta\right)$ & $(T, r, Y)$ & كمى برتر & r \\
\hline$\left(\cdot / 1 \varepsilon_{0} \cdot / r_{0} \cdot / r \Delta\right)$ & $(f, \Delta, \varphi)$ & خوب & f \\
\hline$\left(\cdot / 1 \mathrm{~F} \cdot / 1 \varepsilon_{\cdot} \cdot / r\right)$ & $(\Delta, 9 . V)$ & نسبتاً خوب & $\Delta$ \\
\hline$(\cdot / 1 \mathrm{r} \cdot \cdot / \cdot, / F / 19)$ & $(\mathcal{G} 、 \vee ، \wedge)$ & بسيار خوب & 4 \\
\hline 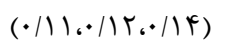 & $(\mathrm{V} ، 1.9)$ & عالى & v \\
\hline$(\cdot / 1 . \cdot / 11 . \cdot / 14)$ & $(1,9.1 \cdot)$ & برترى مطلق & $\wedge$ \\
\hline
\end{tabular}

خبركان در اين مطالعه شامل خبركان دانشگاهى و صنعتى بود.

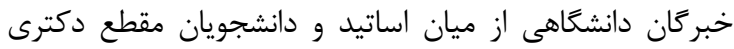

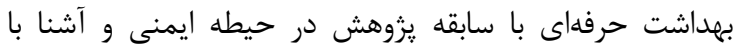

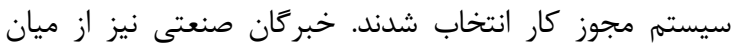

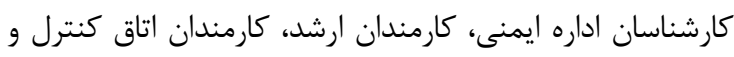

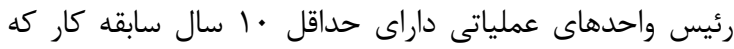
داراى صلاحيت صدور و نظارت بر روند اجراى سيستم مجوز كار اردي

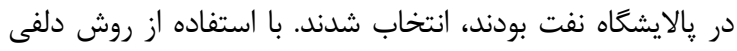

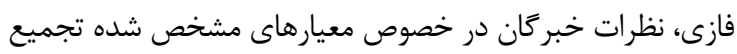

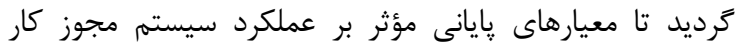

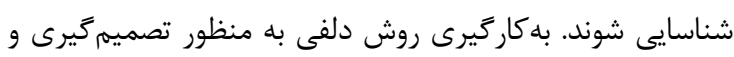

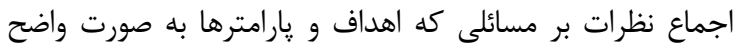

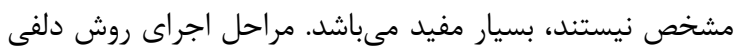
فازى در شكل ا نشان داده شده است.

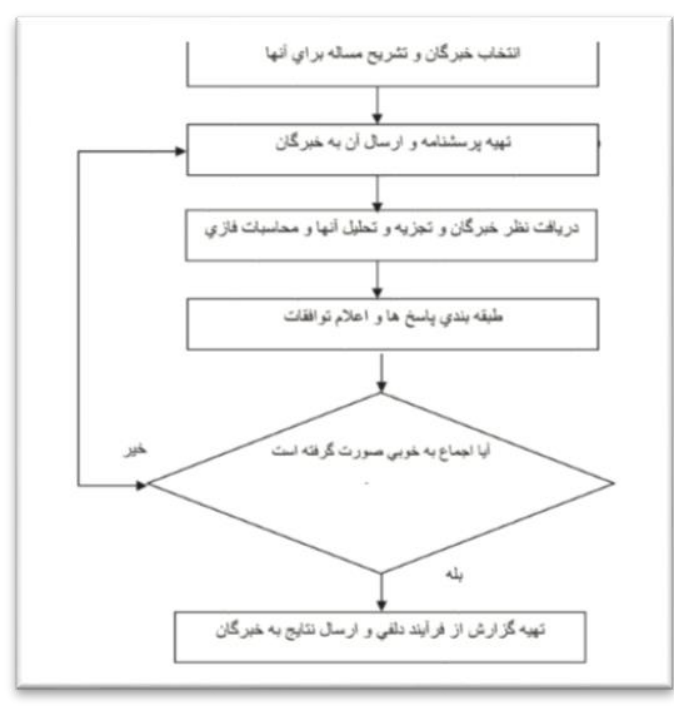

شكل ا: مراحل اجراى روش دلفى فازى

در كام نخست، يرسشنامهاى بدون نام و نشان براى ها خبره

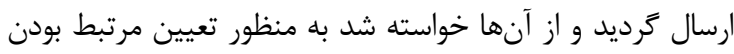

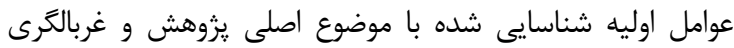

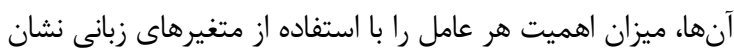

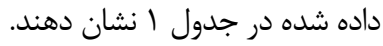

جدول ا: عبارت زبانى به كار رفته در روش دلفى فازى و طيف

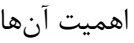

\begin{tabular}{|c|c|}
\hline امتياز طيف اهميت & عبارت زبانى \\
\hline 1 & بسيار كم \\
\hline r & كم \\
\hline r & متوسط \\
\hline f & 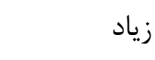 \\
\hline$\Delta$ & بسيار زياد \\
\hline
\end{tabular}


آمده با استفاده از روش گو گوس و بوجر ( Gogus and (Boucher

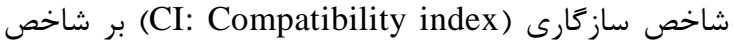
تصادفى محاسبه گرديد [ع|1]. حاصل نرخ ناسازگارى تمام ماتريسها كمتر از // • محاسبه گَرديد؛ بنابراين نتايج قابل اعتماد تلقى شدند. در اين مطالعه به منظور انجام محاسبات

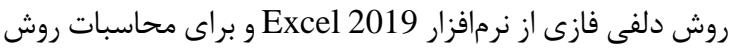

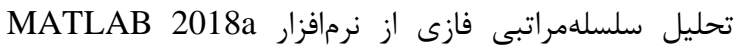
استفاده گَرديد.

\section{نتايجه}

در اين مطالعه از له خبره به منظور انجام روش دلفى فازى و

تحليل سلسلهمراتبى فازى استفاده گرديد. ميانگين سنى خبر خطان

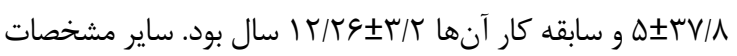
دموَرافيك افراد خبره در جدول ب نمايش داده شده است.

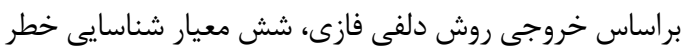

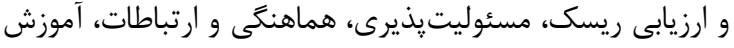

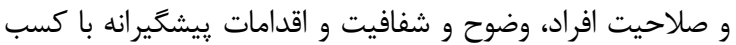
اجماع بالاى • V درصد به عنوان معيارهاى مؤثر بر عملكرد سيستم

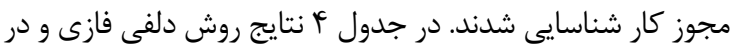

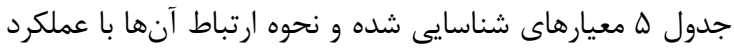
سيستم مجوز كار به تفكيك ارائه شدهاند.

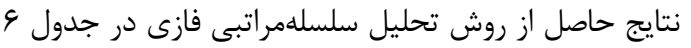

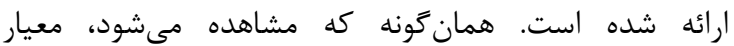

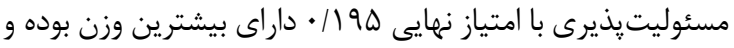

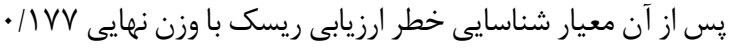

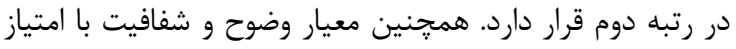

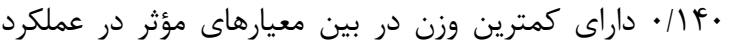

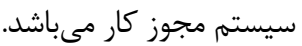

$$
a_{i j}=\left[\prod_{k=1}^{k} \tilde{a}_{i j k}\right]^{\frac{1}{k}} \quad k=1.2 \ldots k \quad(\Delta) \text { (ه) }
$$

ماتريس مقايسه است كه بر آيند قضاوتهاى خبر كان مىباشد. در ادامه، ماتريس مقايسات زوجى با بهكاركيرى اعداد فازى مهي

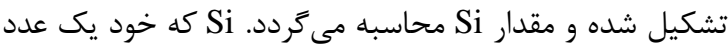

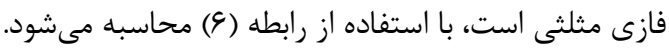
$S_{i}=\sum_{j=1}^{m} M_{g i}^{j} \otimes\left[\sum_{i=l}^{n} \sum_{j=l}^{m} M_{g i}^{j}\right]^{-1} \quad$ (9) در اين رابطه، i بيانكر شماره سطر بوده و j نشاندهنده شماره ستون است. مى باشد. $\left[\sum_{i=l}^{n} \sum_{j=l}^{m} M_{g i}^{j}\right]^{-1}, \sum_{i=l}^{n} \sum_{j=l}^{m} M_{g i}^{j} ، \sum_{j=1}^{m} M_{g i}^{j}$ مقادير بر اساس روابط رياضى شماره V تا وتعيين شدند.

$\sum_{j=1}^{m} M_{g i}^{j}=\left(\sum_{j=1}^{m} l_{j} \cdot \sum_{j=1}^{m} m_{j} \cdot \sum_{j=1}^{m} u_{j}\right) \quad$ ( ( ) $\sum_{i=l}^{n} \sum_{j=l}^{m} M_{g i}^{j}=\left(\sum_{j=1}^{n} l_{j} \cdot \sum_{j=1}^{n} m_{j} \cdot \sum_{j=1}^{n} u_{j}\right)$ ( ) (^) $\left[\sum_{i=l}^{n} \sum_{j=l}^{m} M_{g i}^{j}\right]^{-1}=\left(\frac{1}{\sum_{i=1}^{n} u_{i}} \cdot \frac{1}{\sum_{i=1}^{n} m_{i}} \cdot \frac{1}{\sum_{i=1}^{n} l_{i}}\right)$ (9)

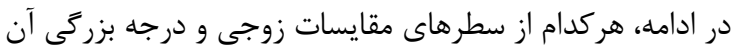

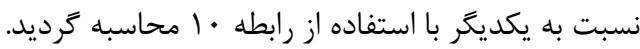
$\mathrm{V}\left[M_{2} \geq M_{1}\right]=\operatorname{hgt}\left[M_{1} \cap M_{2}\right]=\mu_{M_{2}}(d)=$
$\left\{\begin{array}{cc}1 & \text { if } m 2 \geq m 1 \\ \frac{l 1-u 2}{\left(M_{2}-u 2\right)-(m 1-l 1)} & \text { if } l 1 \geq u 2 \\ & \text { other wise }\end{array}\right.$ در نهايت براى اطمينان از قابل اعتماد بودن نتايج به دست

جدول r: مشخصات دموكرافيك خبر كان حاضر در مطالعه

\begin{tabular}{|c|c|c|}
\hline انحراف معيار ذميانگين (درصد) & & 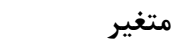 \\
\hline$\Delta \pm r V / \Lambda$ & & 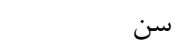 \\
\hline $\mid r / r \pm r g / r$ & & سابقه كار \\
\hline is & كارشناسى & \\
\hline rT & 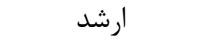 & مدرك تحصيلى \\
\hline$r \cdot$ & 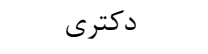 & \\
\hline r. & هيأت علمى & \\
\hline rF & افسر ايمنى & \\
\hline$\wedge$ & رئيس نوبتكارى & ش: \\
\hline TF & كارمند ارشد & سعل \\
\hline r & رئيس واحد & \\
\hline$r \cdot$ & كارمند اتاق كنترل & \\
\hline
\end{tabular}


جدول †: خروجى روش دلفى فازى

\begin{tabular}{|c|c|c|c|c|c|c|c|c|c|c|c|c|}
\hline \multirow[b]{2}{*}{ :े } & \multirow[b]{2}{*}{$\frac{\hat{3}}{\hat{3}}$} & \multirow{2}{*}{ 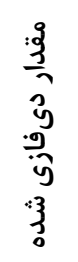 } & \multicolumn{3}{|c|}{ تجميع مقدار فازى } & \multicolumn{5}{|c|}{ طيف اهميت } & \multirow[b]{2}{*}{ 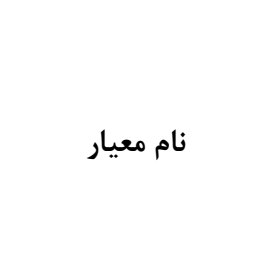 } & \multirow[b]{2}{*}{ رديف } \\
\hline & & & $\mathbf{U}$ & $\mathbf{M}$ & $\mathbf{L}$ & 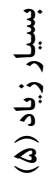 & ?3 & 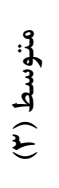 & E & $\begin{array}{l}3: \\
\hat{z} \\
\stackrel{1}{\vdots}\end{array}$ & & \\
\hline يذيرش & $\cdot / \mathrm{A} \Lambda$ & $4 / \pi)$ & $\Delta$ & $F / l r$ & r & $r$ & rt & - & - & - & شناسايى خطر و ارزيابى & 1 \\
\hline بذ بذرش & $\cdot / V T$ & $F / T$ & $\Delta$ & r/99 & r & r & 11 & r & - & - & اقدامات يِيشَيرانه & r \\
\hline رد & $\cdot / 4 \wedge$ & $r / 1 \Lambda$ & $\Delta$ & T/MG & 1 & $r$ & IT & $r$ & $\Delta$ & r & تمديد شيفت & r \\
\hline رد &. $\mid 94$ & $r / 9 V$ & $\Delta$ & r/AF & r & $r$ & 19 & r & r & - & يايش سيستم مجوز كار & r \\
\hline ل بذيرش & $\cdot / N T$ & $r / \Delta$ & r & r & r & $r$ & 11 & r & r & - & آموزش و صلاحيت افراد & $\Delta$ \\
\hline بذيرش & .194 & $r / r q$ & $\Delta$ & $r / \cdot \Lambda$ & r & $r$ & rr & - & - & - & مسئوليت يذيرى & 4 \\
\hline رد & $\cdot / \Delta 9$ & $r / T \Lambda$ & $\Delta$ & $r / \Delta \varphi$ & 1 & $r$ & if & 9 & r & 1 & مدت اعتبار مجوز كار & v \\
\hline ل يذيرش & ./VG & $r / r v$ & r & $r / T F$ & r & r & 19 & $r$ & - & - & وضوح و شفافيت & $\wedge$ \\
\hline ل بذيرش & $\cdot / \wedge$ & $r / 9 \Lambda$ & $\Delta$ & r/re & $r$ & r & $r \cdot$ & $r$ & - & - & هماهنكى و ارتباطات & 9 \\
\hline د) & $\cdot / 4$ & $r / 9$ & $\Delta$ & $r / \Lambda$ & 1 & $\Delta$ & $\Delta$ & 1. & 1 & f & بركشت مجوز كار & 1. \\
\hline
\end{tabular}

جدول ه: معيارهاى شناسايى شده براساس روش دلفى و اهميت آنها در سيستم مجوز كار

\begin{tabular}{|c|c|c|}
\hline اهميت معيار در سيستم مجوز كار & معيار & رديف \\
\hline 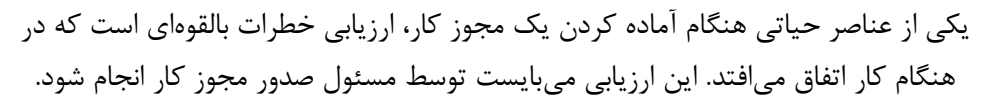 & 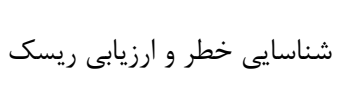 & 1 \\
\hline 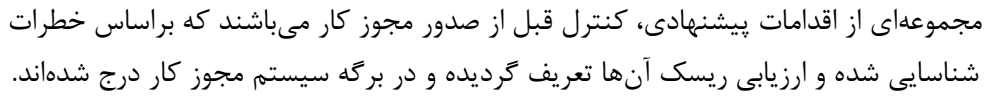 & اقدمات يِشَيرانه & r \\
\hline عملكرد و ميزان اثربخشى يك سيستم به ميزان مسئوليتيذيرى اعضاى سيستم بستخى دارد. & 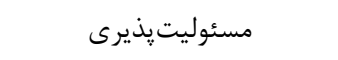 & r \\
\hline 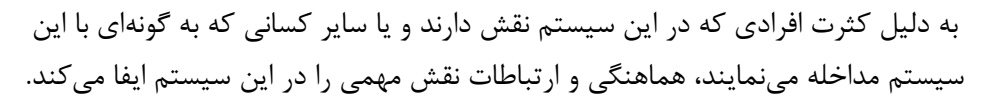 & هماهنَّى و ارتباط & f \\
\hline عملكرد و اثربخشى سيستم به ميزان دقت و مهارت اعضاى تشكيلدهنده آن بستكى دارد. & آموزش و صلاحيت افراد & $\Delta$ \\
\hline 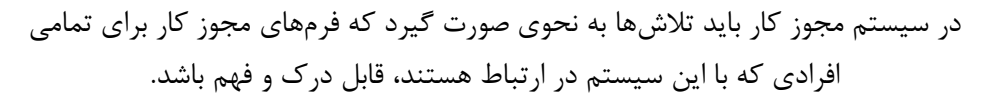 & وضوح و شفافيت & 9 \\
\hline
\end{tabular}

جدول 9: نتايج روش تحليل سلسلهمراتبى فازى و اولويتبندى معيارها براساس وزن نهايى

\begin{tabular}{|c|c|c|c|c|}
\hline رتبه براساس ميزان وزن نرمال & وزن نرمال & وزن ن مال نشده & 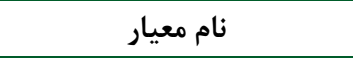 & رديف \\
\hline r & $\cdot / 1 \mathrm{VV}$ &.$/ 91$ & شناسايى خطر و ارزيابى ريسك & 1 \\
\hline$\Delta$ & $\cdot / N Q F$ & $\cdot / v 9$ & اقدامات بِيشكير انه & r \\
\hline 1 & .1190 & 1 & مسئوليت پذيرى & r \\
\hline r & $\cdot / 19$ & - /AT & آموزش و صلاحيت افراد & r \\
\hline 4 & $\cdot / / F$. & $\cdot / V T$ & وضوح و شفافيت & $\Delta$ \\
\hline r & $\cdot / 1 \mathrm{VI}$ & $\cdot / \mathrm{M}$ & هماهنتى و ارتباطات & द \\
\hline
\end{tabular}


و كزارش نمود كه يكى از عدم انطباقات مهام در سيستم مجوز كار،

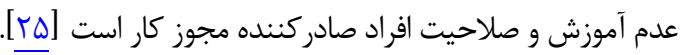

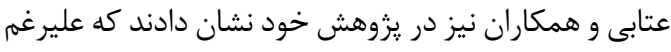

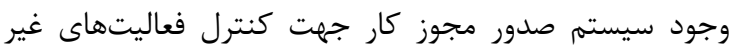

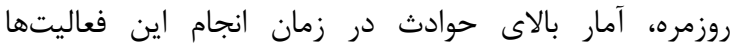

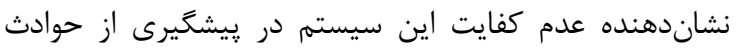

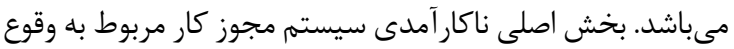

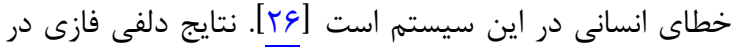

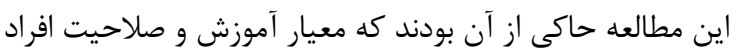
به عنوان يكى از معيارهاى مؤثر بر عملكرد صحيح سيستم مجوز

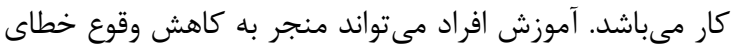
انسانى در اين سيستم شود. در اين راستا، در مطالعه جهانكيرى

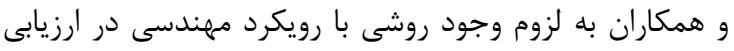

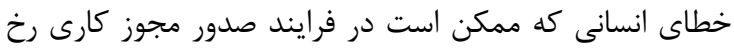
داده و كارايى سيستم را كاهش دهد، تأكيد شده است كه با بانتايج

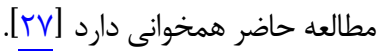

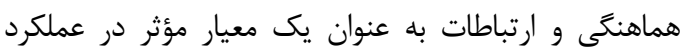
سيستم مجوز كار ميان افرادى است كه به نحوى درئ در اين سيستم

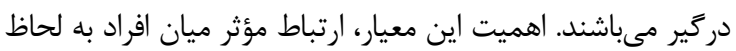
جلوكيرى از ايجاد تداخل، موازى كارى و يا ناديده كرفتن الزاميات

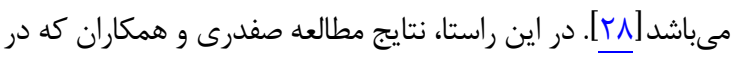
واحدهاى ستادى شركت ملى كاز ايران انجام شد، نشان دادند كه

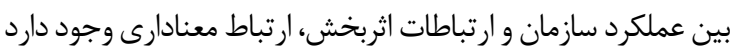

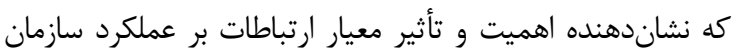

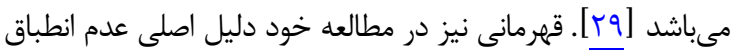

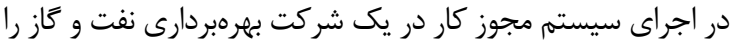
عدم وجود روشى براى ارزيابى كل عوامل و معيارهاى مؤثر بر بر عملكرد برد

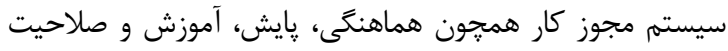

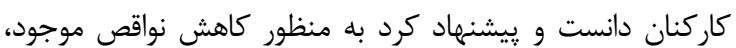
سيستم مجوز كار اين عوامل مورد ارزيابى قرار بخيرد [ـــ].

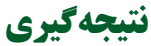

مطالعه حاضر با هدف شناسايى و اولويتبندى معيارهاى مؤثر بر عملكرد سيستم مجوز كار در صنايع فرايندى باريا بهكاركيرى روش دلفى و تحليل سلسلهمراتبى فازى انجام شد. نتايج حاصل از روش دلفى نشان دادند كه برائ دائ عملكرد صحيح

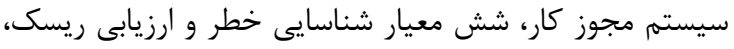

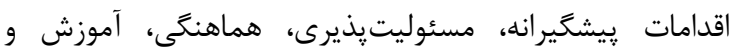
صلاحيت افراد و وضوح و شفافيت نقش مهمى دارند. همجنين

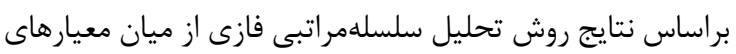

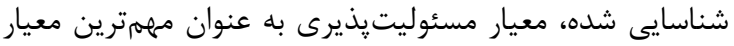

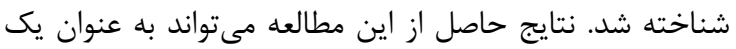

در مطالعه حاضر به شناسايى و اولويتبندى معيارهاى مؤثر

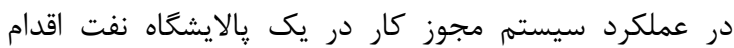

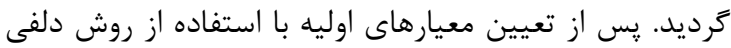

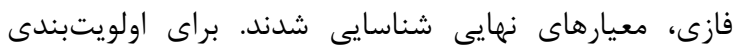

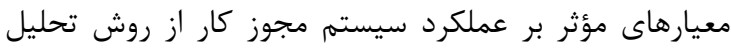

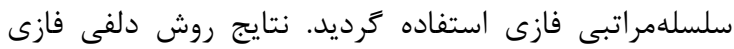
نشان دادند كه شش معيار شناسايى خطر و ارزيابى ريسك،

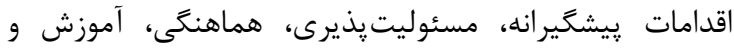
صلاحيت افراد و وضوح و شفافيت، معيارهاى نهايى مؤثر در عملكرد سيستم مجوز كار مى وباشند. در مطالعات متعددى كه به بررسى وضعيت عملكرد سيستم

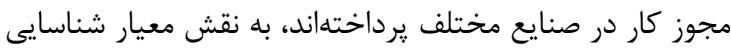
خطر و ارزيابى ريسك در اين سيستم اشاره شده است.

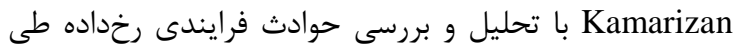

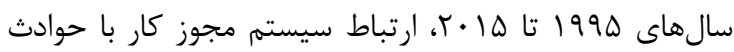

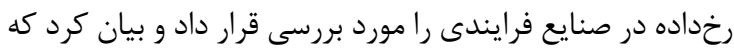

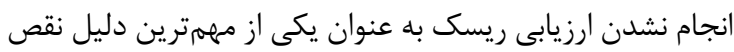

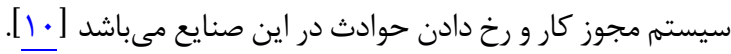

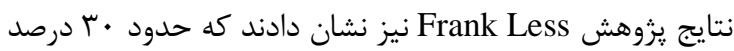
از سيستمهاى صدور مجوز كارى بررسى شده در صنايع ندايع

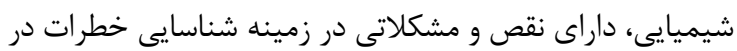

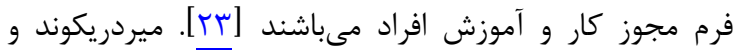

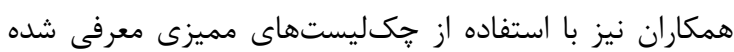
توسط SHELL و SHEL به ارزيابى عملكرد سيستم مجوز

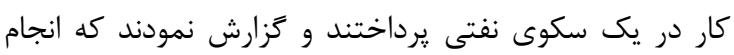

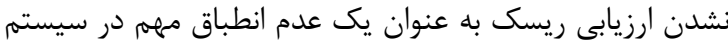

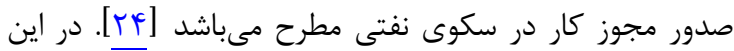

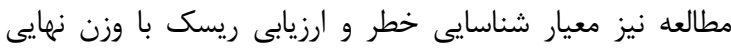
/lVV

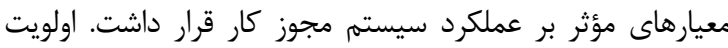

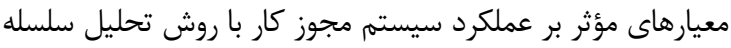

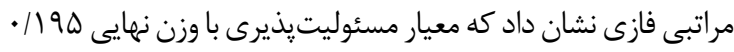
به عنوان مهمترين معيار مؤثر بر عملكرد سيستم مجوز كار دار در مطالعيد

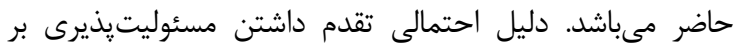

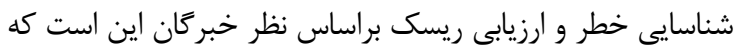

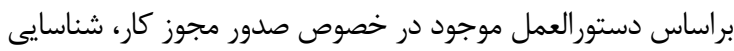
خطر و ارزيابى ريسك مىبايست در محل انجام كار صورت كيرد؛ امداس

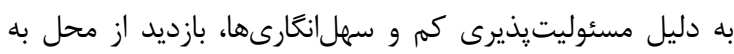
درستى انجام نمىشود. دليل اين مسئوليتيذيرى كم و سهل إنغارى

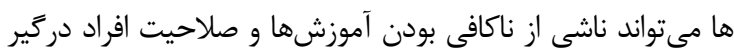

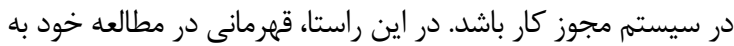

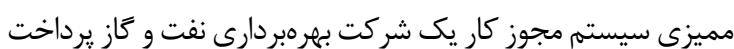




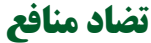

هيج گَونه تضاد منافعى بين نويسندكًان حاضر در اين مطالعه

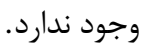

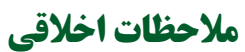

اين مقاله بخشى از پايان نامه مقطع كارشناسى ارشد با كد

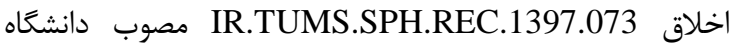

$$
\text { علوم يزشكى تهران مى باشد. }
$$

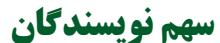 \\ در اين مطالعه على كريمى و سيد ابولفضل ذاكريان در \\ طراحى و روش شناسى مطالعه ، سيد مهدى موسوى درى در مرحله

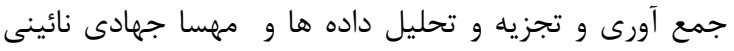 درمرحله نعارش و اصلاحات مقاله نقش داشته اند . تجريه}

$$
\begin{aligned}
& \text { حمايت مالى } \\
& \text { اين مقاله با حمايت اداره يزوهش و توسعه شركت يالايش نفت }
\end{aligned}
$$

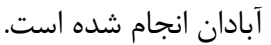

\section{REFERENCES}

1. Wang J, Fu G, Yan M. Investigation and analysis of a hazardous chemical accident in the process industry: triggers, roots, and lessons learned. Processes. 2020;8(4):477. DOI: 10.3390/pr8040477

2. Baalisampang $\mathrm{T}$, Abbassi R, Garaniya V, Khan $\mathrm{F}$, Dadashzadeh M. Modelling an integrated impact of fire, explosion and combustion products during transitional events caused by an accidental release of LNG. Proc Saf Environ Protec. 2019;128:259-72. DOI: 10.1016/j.psep.2019.06.005

3. Hayes J. Disaster incubation: Grenfell Tower's unnecessary lessons. Construc Res Innovat. 2017;8(3):76-9. DOI: 10.1080/20450249.2017.1367559

4. Mousavi SM, Karimi A, Zakerian SA, Makvandi G, Mehravar M. Development and validation of work permit system performance assessment questionnaire, a case study in an Iranian oil refinery. Arch Hyg Sci. 2019;8(3):154-62. DOI: 10.29252/ArchHygSci.8.3.154

5. Zarei E, Mohammadfam I, Azadeh A, Khakzad N, Mirzai M. Dynamic risk assessment of chemical process systems using Bayesian Network. Iran Occup Health J. 2018;15(3):103-17. [Persian]

6. Misuri A, Moreno VC, Quddus N, Cozzani V. Lessons learnt from the impact of hurricane Harvey on the chemical and process industry. Reliabil Eng Syst Saf. 2019;190:106521. DOI: 10.1016/j.ress.2019.106521

7. Lees F. Lees' Loss prevention in the process industries: hazard identification, assessment and control. Oxford: Butterworth-Heinemann; 2012.

8. Zimmerman J, Haywood B. Process safety management best practice: safe work permit management system. The ASSE Professional Development Conference and Exposition, Denver, Colorado, USA; 2017.

9. Guidance on permit-to-work systems, A guide for the petroleum, chemical and allied industries. Merseyside: Health and Safety Executive; 2005.

10. Yan CK, Siong PH, Kidam K, Ali MW, Hassim MH, Kamaruddin MJ, et al. Contribution of permit to work to process safety accident in the chemical process industry. Chem Eng Transact. 2017;56:883-8.DOI: 10.3303/CET1756148

11. Jusoh N, Ali MW, Abdullah TA, Husain A. The verification
راهنماى كاربردى جهت برنامهريزى به منظور اجراى اقدامات

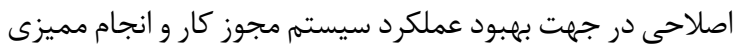
به منظور شناسايى نقاط قوت و ضعف اجراى سيستم مجوز كار در صنايع فرايندى توسط سريرستان و كارشناسان ايمنى و ورئى

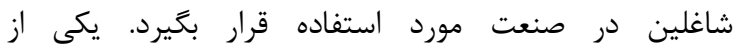
محدوديتهاى مطالعه حاضر اين بود كه در اين مطالعه از ارتباط

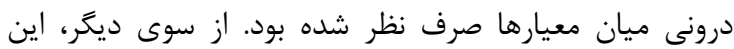

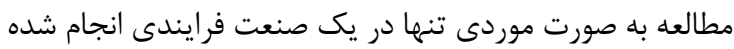

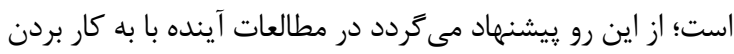
روشهاى تصميمگيرى جند معياره كه توانايى تحليل ارتباطات

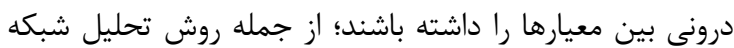
(Analytical Network Process) ANP مشابه ديگر با جامعه آمارى متفاوت، تأثير ارتباط بين معيارها سنجيده شده و وزن نهايى آنها با مطالعه حاضر مقايسه گردد.

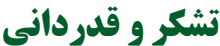

بدينوسيله از همكارى خبر گان دانشعاهى و صنعتى شاغل

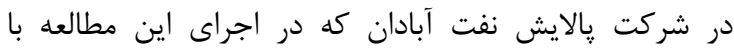

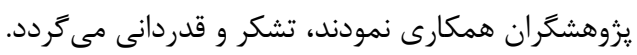

result of permit to work assessment in occupational accident using fault tree analysis. Mater Sci Eng. 2020;808(1):012022. DOI: 10.1088/1757-899X/808/1/012022

12. Mousavi SM, Karimi A, Zakerian SA, Jahadi Naeini M. Factors affecting performance of permit to work system: a case study in an oil refinery. Arch Occup Health. 2020;4(4):863-9. DOI: 10.18502/aoh.v4i4.4512

13. Dambros JW, Trierweiler JO, Farenzena M. Oscillation detection in process industries-Part I: review of the detection methods. J Proc Control. 2019;78:108-23. DOI: 10.1016/ j.jprocont.2019.04.002

14. Zanker J, Scott D, Reijnierse E, Brennan-Olsen S, Daly R, Girgis C, et al. Establishing an operational definition of sarcopenia in Australia and New Zealand: Delphi method based consensus statement. J Nutr Health Aging. 2019; 23(1):105-10. PMID: 30569078 DOI: $10.1007 / \mathrm{s} 12603-018-$ 1113-6

15. Hernandez NB, Ruilova Cueva MB, Mazacón BN. Prospective analysis of public management scenarios modeled by the Fuzzy Delphi method. Neutrosophic sets and systems. New Mexico: University of New Mexico; 2019. P. 17.

16. Moradirad R, Haghighat M, Yazdanirad S, Hajizadeh R, Shabgard Z, Mousavi SM. Selection of the most suitable sound control method using fuzzy hierarchical technique. $J$ Health Saf Work. 2019;8(4):371-82. [Persian]

17. Jain V, Sangaiah AK, Sakhuja S, Thoduka N, Aggarwal R. Supplier selection using fuzzy AHP and TOPSIS: a case study in the Indian automotive industry. Neural Comput Appl. 2018;29(7):555-64. DOI: 10.1007/s00521-016-2533-Z

18. Adli J, Omidvari M. Assessing the risk of crisis in gas distribution networks using the FAHP-PROMETHEE II method (Case study of Qazvin Province Gas Company). Iran Occup Health. 2020;17(1):1-14. [Persian]

19. Mousavi SM, Abbasi M, Yazdanirad S, Yazdanirad M, Khatooni E. Fuzzy AHP-TOPSIS method as a technique for prioritizing noise control solutions. Noise Control Eng J. 2019;67(6):415-21. DOI: 10.3397/1/376738

20. Kaur R, Mittal S. Multi criteria based handoff using FAHP and Fuzzy Inference System. 2019 International Conference on Data Science and Communication (IconDSC), Bangalore, 
India; 2019. DOI: 10.1109/IconDSC.2019.8816874

21. Jahangiri M, Molaei Far H, Honarbaksh M, Farhadi P, Khani B, Rajabi F. Prioritizing strategies of skin exposure with chemical in a painting company using fuzzy analytical hierarchy process \& Topsis. Health Saf Work. 2019;8(4):40918. [Persian]

22. Asghari M, Nassiri P, Monazzam MR, Golbabaei F, Arabalibeik H, Shamsipour AA, et al. Determination and weighting the effective criteria in selecting a heat stress index using the Delphi technique and fuzzy analytic hierarchy process (FAHP). J Health Saf Work. 2017;7(1):23-32. [Persian]

23. Van Rooij B, Fine A. Toxic corporate culture: assessing organizational processes of deviancy. Administ Sci. 2018;8(3):23. DOI: 10.3390/admsci8030023

24. Majid ND, Shariff AM, Zaki NA. Compliance of hot work permit to process safety management (PSM) regulation. Appl Mechan Mater. 2014;625:418-21. DOI: 10.4028/www.scien tific.net/AMM.625.418

25. Mirderikvand H, Nassiri P, Mansouri N. Evaluation and comparative compare PTW system performance in an offshore oil platform. Hum Environ. 2011;9(4):15-20.
[Persian]

26. Ghahramani A. Permit to work system conformity analysis based on the system standard criteria in an oil and gas extraction company. Iran Occup Health J. 2007;4(1):10-4. [Persian]

27. Ghasemi A, Atabi F, Golbabaei F. Human error classification for the permit to work system by SHERPA in a petrochemical industry. J Occup Hyg Eng. 2015;2(3):66-73. [Persian]

28. Jahangiri M, Hobobi N, Keshavarzi S, Hosseini AA. Determination of human error probabilities in permit to work procedure. Saf Reliabil Complex Eng Syst. 2015;138:294550. DOI: 10.1201/b19094-387

29. Hoboubi N, Jahangiri M, Keshavarzi S. Introduction of engineering approach technique in quantitative human error assessment; case study in permit to work system of a petrochemical plant. Iran Occup Health. 2014;11(5):1-9. [Persian]

30. Safdary M, Afrazeh A, Ebrahimi M, Azami A. The role of human resource management, organizational structure and culture in promoting corporate entrepreneurship (Case study: petrochemical research \& technology company). Hum Res Manag Oil Ind. 2014;5(20):159-80. [Persian] 